
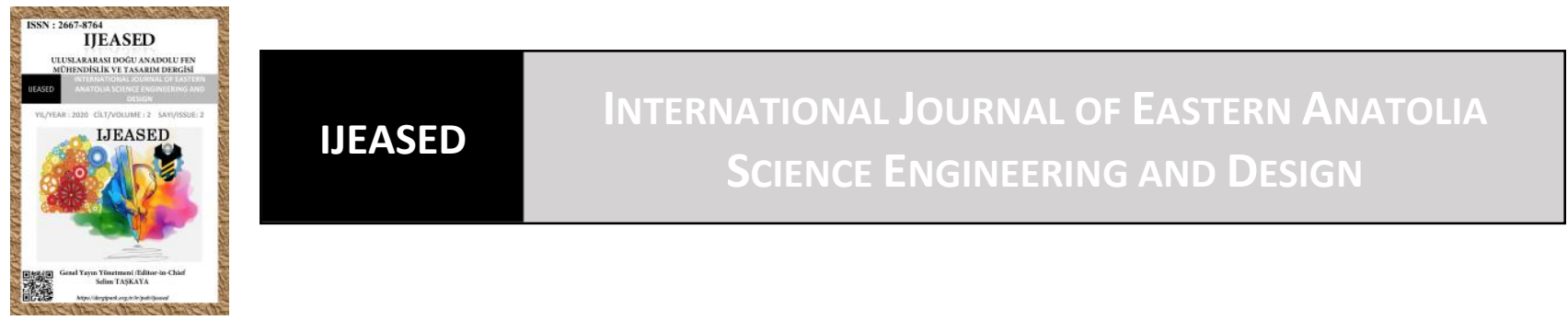

\author{
Uluslararası Doğu Anadolu Fen Mühendislik ve Tasarım Dergisi \\ ISSN: 2667-8764, 2(2), 275-295, 2020 \\ https://dergipark.org.tr/tr/pub/ijeased
}

Araştırma Makalesi / Research Article

Doi: $\underline{10.47898 / \text { ijeased.792519 }}$

\title{
Bazı Dayanıklı Şeker Pancarı Çeşitlerinin Rhizoctonia spp.'ye Karşı Reaksiyonlarının Belirlenmesi
}

\author{
Meltem AVAN ${ }^{1, a^{*}}$, Yakup Zekai KATIRCIOĞLU ${ }^{1, b}$ \\ ${ }^{1, a}$ Ankara Universitesi, Ziraat Fakültesi, Bitki Koruma Bölümü, 06110, Türkiye. \\ ${ }^{1, b}$ Ankara Universitesi, Ziraat Fakültesi, Bitki Koruma Bölümü, 06110, Türkiye.
}

\begin{tabular}{l|l|l}
\hline \multicolumn{1}{c|}{ Yazar Kimliği / Author ID (ORCID Number) } & \multicolumn{3}{|c}{ Makale Süreci / Article Process } \\
\hline "Sorumlu Yazar / Corresponding author : & Geliş Tarihi / Received Date $:$ & 09.09 .2020 \\
meltem_avn@ hotmail.com & Revizyon Tarihi / Revision Date : & 03.10 .2020 \\
\hline iD https://orcid.org/0000-0002-2939-8177, M. Avan & Kabul Tarihi / Accepted Date : & 17.10 .2020 \\
iD https://orcid.org/0000-0001-5308-9414, Y.Z.Katırcığlu & Yayım Tarihi / Published Date : & 15.12 .2020 \\
\hline
\end{tabular}

Alıntı /Cite : Avan, M., Katırcıŏglu, Y.Z. (2020). Bazı Dayanıklı Şeker Pancarı Çeşitlerinin Rhizoctonia spp.'ye Karşı Reaksiyonlarının Belirlenmesi, Uluslararası Doğu Anadolu Fen Mühendislik ve Tasarım Dergisi, 2(2), 275-295.

\begin{abstract}
Özet
Şeker pancarında fide ve kök çürüklüklerine sebep olan fungal hastalıklar, bu bitkide önemli verim ve kalite kayıplarına sebep olmaktadır. Ülkemizde Konya bölgesi, şeker pancarı üretim alanlarının yaklaşık \%35.5'ini elinde tutan önemli bir şeker pancarı üretim alanıdır. Son yıllarda Konya bölgesinde kök çürümesi ve çökertenin meydana getirdiği verim kayıplarında önemli artışlar meydana gelmiştir. Çeşit reaksiyon çalışmaları, 2015-2017 büyüme dönemlerinde, Konya bölgesinde şeker pancarı taç ve kök çürüklüğüne neden olan Rhizoctonia spp.'lerden tespiti yapılan AG-2-2-IIIB, AG4-HGI, AG-4-HGII, AG-4-HGIII, AG-A ve AG-K izolatlarına karşı denenmiştir. Bu çalışmada, 10 dirençli şeker pancarı çeşidi ve izolatların anastomosis grupları belirlenen ve tüm AG'leri temsil eden \%50'nin üzerinde en yüksek virülansa sahip izolatlarından birer adet seçilerek, saksı denemelerinde inokulum tabaka tekniği kullanılarak denemeye tabi tutulmuştur. Dayanıklı şeker pancarı çeşitleri, Rhizoctonia kök çürüklüğü ile entegre bir yönetimin parçasıdır. Denemeler sonucunda çok çekirdekli Rhizoctonia izolatlarında inokulum seviyesinin ve patojenin yüksek olan virülensliğinin de etkisi sonucu, çeşitlerde bir dayanıklılık tespit edilmemiştir.Virülensliği daha düşük olan iki çekirdekli Rhizoctonia'lar da ise AG-A için Iguana, Valentina, Eldorado, Rodeo, Lider ve 5K614 çeşitleri, AG-K için ise Lider ve Valentina çeşitleri yüksek dayanıklı olarak belirlenmiştir.
\end{abstract}

Anahtar Kelimeler: Beta vulgaris, Çökerten, Dayanıklı çeşitler, Rhizoctonia spp., Yapay inokülasyon. 


\section{Determination of Reactions of Some Resistant Sugar Beet Varieties against Rhizoctonia spp.}

\section{Abstract}

Fungal diseases causing rotting of seedlings and roots on sugar-beet are one of the major problems for significant yield and quality losses. In Turkey, Konya region is an important sugar-beet production area with approximately $35.5 \%$ of Turkey production. In recent years, there has been significant increases in yield losses caused by root rot and dampingoff in the Konya region. Resistant sugar beet variety reaction studies were tested against AG-2-2-IIIB, AG-4-HGI, AG4-HGII, AG-4-HGIII, AG-A and AG-K isolates identified from Rhizoctonia spp., which cause sugar beet crown and root rot in Konya region, during the growing periods of 2015-2017. In this study, 10 resistant sugarbeet varieties and anastomosis groups of the isolates with the highest virulence above 50\% were selected and each of them was tested by using an inoculum layer technique in the pot experiments. Cultivation of resistant sugar-beet varieties is part of an integrated management with Rhizoctonia root rot. As a result, no effective resistant varieties for multinucleate Rhizoctonia have been detected whereas binucleate Rhizoctonia with lower virulence, Iguana, Valentina, Eldorado, Rodeo, Lider and $5 \mathrm{K6} 14$ varieties for AG-A, Lider and Valentina varieties for AG-K have been determined as high resistant.

Keywords: Beta vulgaris, damping-off, resistant varieties, Rhizoctonia spp., artificial inoculation.

\section{Giriş}

Amaranthaceae familyasından bir endüstri bitkisi olan şeker pancarı (Beta vulgaris L.), Türkiye'de şeker endüstrisinin hammaddesi olarak yetiştirilen, yaklaşı 3 milyon dekarlık alandan 20 bin ton üretimi yapılan önemli bir bitkidir (Anonim, 2017). Türkiye, şeker pancarı üretimi bakımından Fransa, Rusya, ABD ve Almanya' dan sonra 5. sırada yer alarak dünya ülkeleri arasında önemli bir yer edinmiştir (FAOSTAT, 2019). Rhizoctonia solani Kühn (Telemorph:Thanatephorus cucumeris) konukçusu olduğu bitkilerde \%5-20 verim kaybına sebep olan, dünya çapında ekonomik önemi olan, oldukça yaygın ve patojenik olan toprak kökenli bir fungustur. Rhizoctonia fungusu genetik özelliklerine göre çeşitli anastomosis gruplarına ve alt gruplara ayrılır (Ogoshi, 1987). Şimdiye kadar, 13 AG (AG-1'den 13'e) multinükleat $R$. solani ve 19 AG (AG-A'dan AG-I, AG-K, AG-L, AG-O, AG-S, AG-U, AG-W'ye) binükleat Rhizoctonia tanımlanmıştır (Ogoshi, 1987; Carling ve ark., 2002; García ve ark., 2006; Yang ve ark., 2015a, b; Ajayi-Oyetunde ve Bradley, 2017; Dong ve ark., 2017). R. solani toprakta ve birçok konukçusu olduğu bitkilerde hayatta kalabildiğinden dolayı, hastalıkla mücadele ve etkili koruma yöntemleri geliştirmek oldukça zorlaşmıştır (Herr, 1996). Windels ve Nabben (1989) Amerika'da MN R. solani AG-2-2 sebep olduğu şeker pancarı fideleri, taç ve kök çürükleri ve çökertenin çok ciddi ve dünyada birçok yerde tespit edilen bir şeker pancarı hastalığı olduğunu, AG-5 ve binükleat Rhizoctonia'ların da patojenik olmadığını tespit etmiştirlerdir. BN Rhizoctonia grupları arasında da en fazla izole edilen 
anastomosis grup AG-K olduğu bulunmuştur. Berdugo ve ark. (2012)'ya göre dünya çapında AG2-2 anastomosis grubunun, Rhizoctonia kök ve taç çürüklügü ile ilişkili en yıkıcı ve en önemli anastomosis grubu iken AG-4 şeker pancarında çökerten ile ilgili en çok görülen anastomoz grubu olduğunu bildirmiştir. Zhao ve ark. (2019) Çin’ de yaptığı çalışmasında şeker pancarları fidelerinde AG-4, AG-2-2-IIIIB, AG-K, AG-A, AG-5 AG-11, AG-3 gibi anastomosis gruba ait izolatlar1 tespit ederek, AG-4 izolatlarının AG-2-2-IIIB izolatlarından daha virülent olduklarını bildirmişlerdir. Wang ve ark. (2012) şeker pancarında AG-A anastomosis grubu izolatlarını \%53-70 arasında patojen bulurken, Zhao ve ark. 2019'da Çin'de yapmış olduğu çalışmalarında şeker pancarında AGA grubu izolatlarını ortalama $\% 56$ oranında, AG-K grubu izolatlarını ise ortalama $\% 78.7$ oranında patojen olarak tespit etmişlerdir.

Patojeni kontrol etmek için uygulanan en önemli mücadele yollarından biri de Rhizoctonia'ya dayanıklı çeşitlerin kullanımıdır (Buddemeyer ve Märländer, 2004). R. solani patojeninin tarlada birden ortaya çıkabilmesi sebebiyle, hastalığa karşı dayanıklılık çalışmaları daha da zorlaşmıştır (Pierson ve Gaskill, 1961). Kontrollü şartlar dışında, tarlada yapılan denemelerde yapay inokulasyon yöntemi geliştirilmiştir (Engelkes ve Windels, 1996). Bu yöntemle enfekte edilmiş arpa, mısır, darı veya buğday kullanımı uygulamada oldukça zor olduğu kadar elde edilecek sonuçlar da tatmin edici bulunmamaktadır. Hastalık çevresel şartlara ve hastalığın yoğunluğuna göre yıldan yıla ve tarladan tarlaya göre farkl1lık göstermektedir.

$\mathrm{Bu}$ çalışmada dayanıklı şeker pancarı çeşitlerin etkilerini tespit etmek için 10 adet dayanıklı şeker pancarı çeşitleri ve moleküler çalışmalarla tespiti yapılan multinükleat $R$. solani ve binükleat Rhizoctonia spp. izolatlarından virülensliği \%50'nin üzerinde olan izolatlar seçilerek saks1 denemesinde kullanılmıştır.

Bu çalışma ile virülensliği \%100 olan 4 adet mültinükleat $R$. solani izolatları ile virülensliği \%53-69 arasında değişen binükleat Rhizoctonia spp. izolatlarının, dayanıklı şeker pancarı çeşitlerine karşı iklim odası koşullarındaki hassasiyetini değerlendirerek, bu sonuçlarla, yeni sera ve arazi tekniklerini geliştirmesine 1ş1k tutmak hedeflenmiştir.

\section{Materyal ve Metot}

Konya bölgesi şeker pancarları örneklerinden izole edilen Rhizoctonia'ların tür ve anastomosis grupları belirlenmesinde, multinükleat $(\mathrm{MN})$ ve binükleat $(\mathrm{BN})$ Rhizoctonia izolatları, 
kendi aralarında önce koloni morfolojilerine, renklerine ve skleroti yapılarına ve skleroti büyüklük ve renklerine göre gruplara kategorize edilmiş, klasik anastomosis grup tayini yapılmış ve izolatların moleküler yöntemlerle tayini gerçekleştirilmiştir (Avan, 2020). Yapılan moleküler tanılama çalışmaları sonucunda tespit edilen izolatlardan multinükleat Rhizoctonia solani AG-2-2IIIB, AG-4-HGI, AG-4-HGII, AG-4-HGIII anastomosis gruplarının \% 100 virülens izolatları ile, binükleat Rhizoctonia spp. AG-A'nin \% 53 ve AG-K'nın \% 69 virülensliğe sahip, en virülent izolatları reaksiyon çalışmasında kullanılmıştır. Şeker pancarı çeşitleri olarak ıslahçı firmaları tarafından Rhizoctonia, Rhizomonia ve Cercospora veya küllemeye (Erysiphe betae) karşı tolerans olduğu bildirilen ve ülkemizde yaygın kullanılan kök ve şeker verimi yüksek, silolamaya ve makineli hasata uygun Boa, Eldorado, Lider, Mohican, Rodeo, Serenade, Valentina çeşitleri ve aday çeşitlerden Iguana, 5K613, 5K614 isimli 10 adet şeker pancarı çeşitleri temin edilerek denemeler kurulmuştur. (Not: Boa, Eldorado, Lider, Mohican, Rodeo, Iguana isimli çeşitler Sesvanderhave firmasına; Serenade, Valentina, 5K613, 5K614 isimli çeşitler ise KWS firmasına aittir.)

Çeşit reaksiyon denemelerinde, inokulum tabakası tekniği (inoculum layer technique) kullanılarak şeker pancarı fideleri üzerindeki etkileri değerlendirilmiştir (Herr ve ark., 1980). Rhizoctonia izolatları zayıflatılmış PDA (g/l olarak; PDA (Merck) 20, agar 10, su $1000 \mathrm{ml}$ ) besi ortamında geliştirilerek deneme için hazırlanmıştır. Toprak sterilizatöründe steril edilen kum+bahçe toprağı+yanmış çiftlik gübresi, steril saksıların 2/3'ünü dolduracak şekilde aktarılmıştır (Şekil 1 a). Ardından petrilerde geliştirilen Rhizoctonia izolatları yuvarlak tabaka şeklinde toprağın üst kısmına yerleştirilip (Şekil 1 b), üzerlerine saksı başına 10 adet steril tohumlar, dairesel olarak yerleştirilmiştir (Şekil $1 \mathrm{c}$ ). Bu tohumların üzerlerine hazırlanan toprak karışımı ile kapatılarak saksılar sulanmıştır (Şekil 1 d) ve deneme 4 tekerrürlü olacak şekilde tekrarlanmıştır. Kontrol saksılarda herhangi bir patojen diski kullanılmamıştır, sadece steril tohumlar ekilerek, üzeri toprakla kapatılmıştır. Kontrollü şartlarda iklim odasında saksılar $23-24^{\circ} \mathrm{C}$ 'de ve \%60-70 nispi nem koşullarında 12 saat aydınlık 12 saat karanlık koşullarda inkübe edilmiştir. Bu süre içerisinde toprağı nemli tutmak için düzenli sulama yapılmıştır. Bitkilerin çıkışından itibaren çıkan bitkiler ve çıkış sonrası ölen bitkiler kaydedilerek, son değerlendirme ise 6. haftanın sonunda kalan bitkiler sökülerek 0-4 skalasına göre değerlendirilmiştir (Hanson, 2006) (Tablo 1). Ölen bitkilerden örnekler alınarak, yarı güçlü PDA ortamında fungus teşhisleri tekrar yapılmıştır. 
Tablo 1. Hanson (2006) 0-4 hastal1k skalas1

\begin{tabular}{|c|c|}
\hline Değerlendirme & $\begin{array}{l}\text { Skala } \\
\text { Değeri }\end{array}$ \\
\hline Hiç leke olmayan sağlıklı bitki & 0 \\
\hline Hafif gelişme geriliği ve yapraklarda solgunluk & 1 \\
\hline Klorotik yapraklar mevcut ve yaprak kenarlarında nekrozlu görünüm & 2 \\
\hline Kök kısımlarında kuruma, kahverengileşme, yapraklarda ölüm & 3 \\
\hline Ölmüş bitki & 4 \\
\hline
\end{tabular}

Elde edilen verilerden Towsend-Heuberger formülü kullanılarak hastalık yüzdeleri hesaplanmıştır (Towsend ve Heuberger, 1943).

Towsend-Heuberger formülü:

Hastalık Yüzdesi: $\quad \underline{\Sigma}$ (değer alan bitki sayısı X sınıf değeri)

En yüksek skala değeri $\mathrm{X}$ toplam bitki sayısı

Towsend-Heuberger formülüne göre hastalık şiddeti hesaplanarak dayanıklılık seviyesi gruplamaları (I= $\leq \%$ 20: Yüksek düzeyde dayanıklı (HR), II= \% 21-50: Orta düzeyde dayanıklı (MR), III= \% 51-80: Düşük düzeyde dayanıklı (LR), IV=>\% 80: Duyarlı (S) olarak kullanılmıştır. 

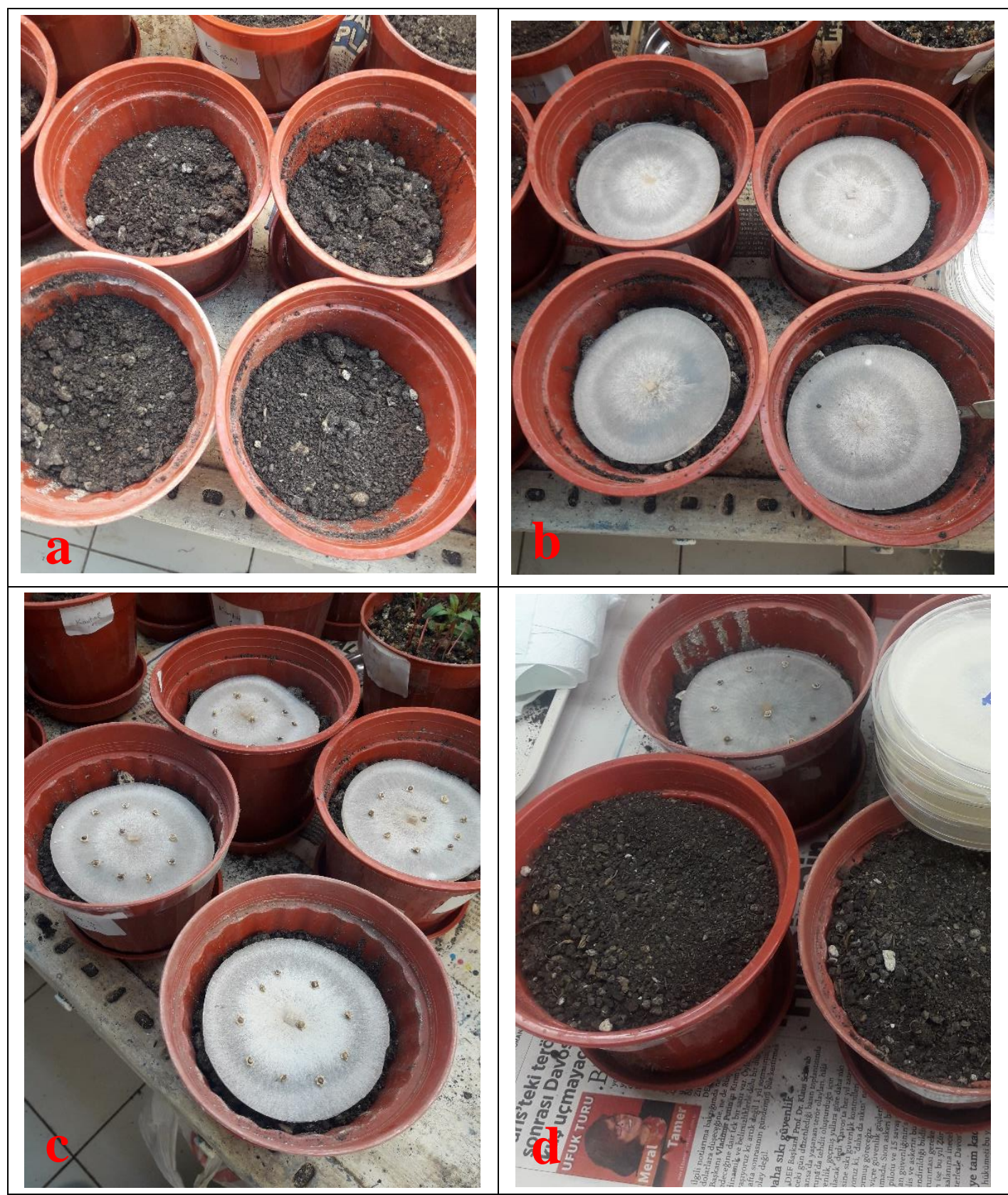

Şekil 1. Rhizoctonia izolatları ve dayanıklı çeşitlerle saksı denemesi kurulum aşamaları

Çeşitlerin multinükleat Rhizoctonia solani ve binükleat Rhizoctonia spp.’ye ait 6 anastomosis grubunun agresif izolatlarına ait \% etkilerini hesaplamak için Abbott formülü kullanılmıştır (Abbott, 1925). 
Çalışmada gözlenen endeks değerleri, hem derecelendirmeye bağlı olarak belirlenmiş değerler olmasından dolayı hem de parametrik bir yöntem olan varyans analizinin ön şartlarını yerine getirmemiş olmasından dolayı veriler parametrik olmayan test yöntemi olan Kruskal-Wallis yöntemi uygulanarak analiz edilmiştir. Uygulanan analiz sonucuna bağlı olarak gerekli olduğu zaman hangi gruplar arasındaki farkların istatistik olarak önemli olduğu çoklu karşılaştırma testi uygulanarak kontrol edilmiştir. Analizler MINITAB istatistik paket programı kullanılarak yapılmıştır.

\section{Bulgular ve Tartışma}

\subsection{Dayanıklı Şeker Pancarı Çeşitlerinin Multinükleat Rhizoctonia solani AG-2-2-IIIB, AG-4-} HGI, AG-4-HGII ve AG-4-HGIII İzolatlarına Karşı Reaksiyonları

Yapılan çeşit reaksiyonu denemeleri, kontrol grubu olarak hazırlanan Iguane (Şekil 2 a), Valentina (Şekil 2 c), 5K614 (Şekil 2 e), 5K613 (Şekil 2 g), Serenade (Şekil 2 i), Rodeo (Şekil 2 k), Mohican (Şekil 2 m), Lider (Şekil 2 o), Eldorado (Şekil 2 r), Boa (Şekil 2 t) çeşitlerinin ve AG-2-2IIIB, AG-4-HGI, AG-4-HGII, AG-4-HGIII anastomosis grubuna ait en yüksek virülenslığe sahip izolatların çeşitler üzerindeki etkilerinin değerlendirilmesi sonucunda, Boa (Şekil $2 \mathrm{u}$ ), Eldorado (Şekil 2 s), Iguana (Şekil 2 b), Lider (Şekil 2 p), Serenade (Şekil 2 j), Valentina (2 d), 5K613 (Şekil 2 h) ve 5K614 (Şekil 2 f) isimli dayanıklı çeşitlere ait tohumlarda çıkışlara bile izin vermeden, ölümünü gerçekleştirmiş, Mohican ve Rodeo çeşitlerinde tesadüfe dayalı olduğu düşünülen bir kaç tohum çıkışı meydana gelmiştir. Dolayısıyla tüm çeşitler bu izolatlara karşı duyarlı olarak tespit edilmiştir. Elde edilen sonuçlar Kruskal-Wallis test yöntemi kullanılarak istatistiki bir değerlendirmeye tabi tutulmuştur. Uygulanan analiz sonucuna bağlı olarak multinükleat AG-2-2IIIB, AG-4-HGI, AG-4-HGII, AG-4-HGIII anastomosis grubuna ait izolatların çeşitler üzerinde ve anastomosis grupları temsil eden hastalıkların kendi aralarında da istatistiksel olarak önemli bir farkı olmadığı kanısına varılmıştır. 


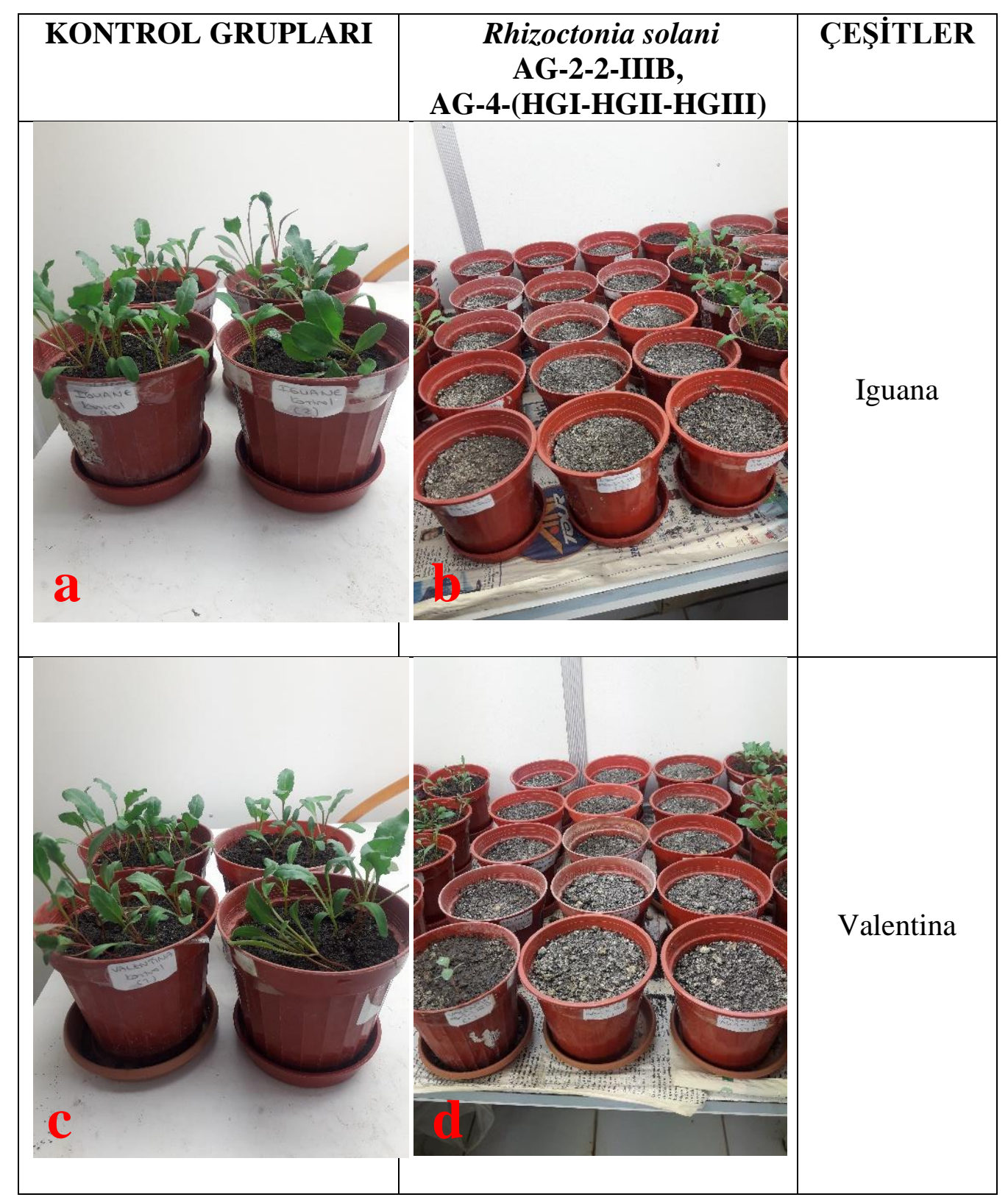




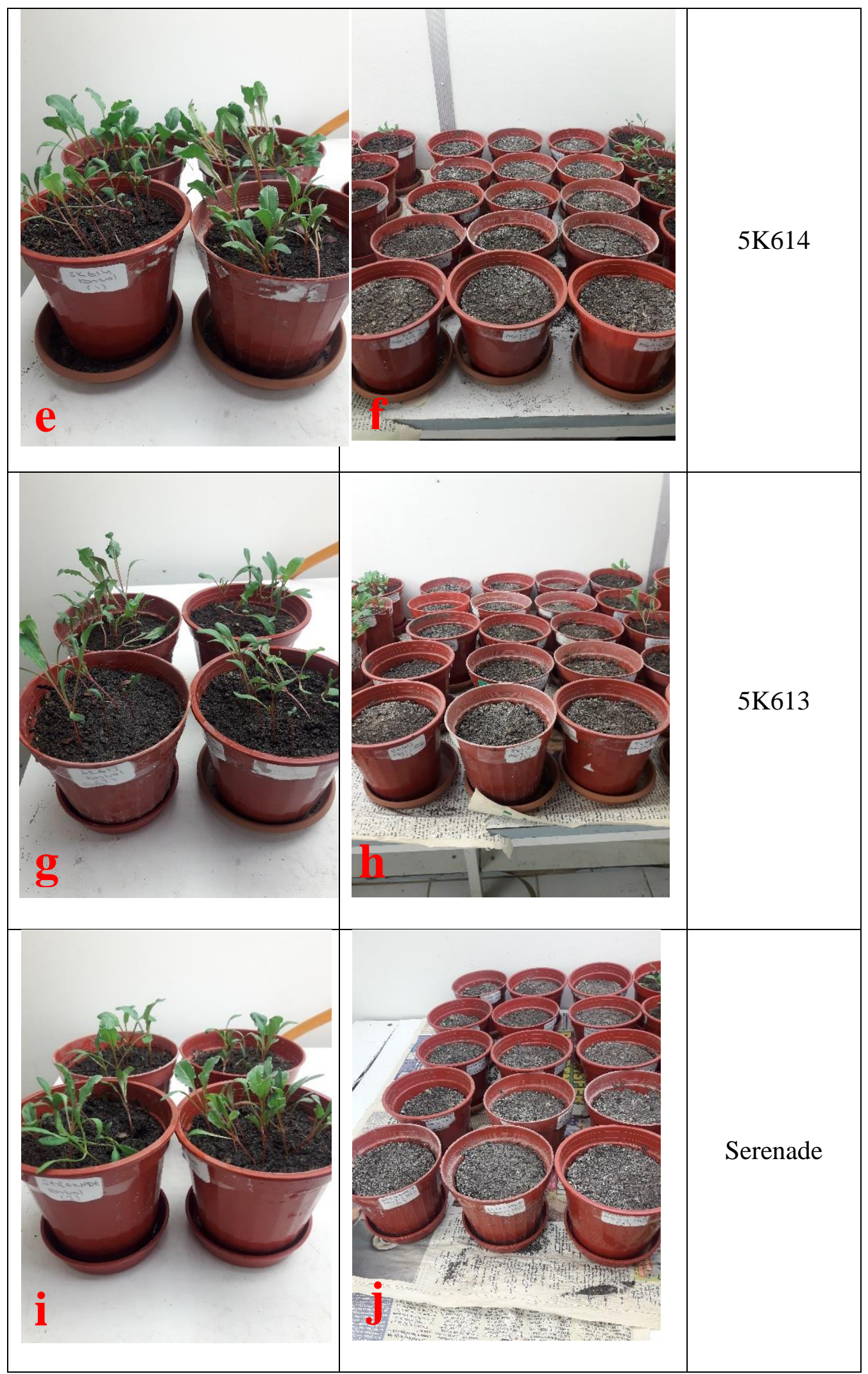




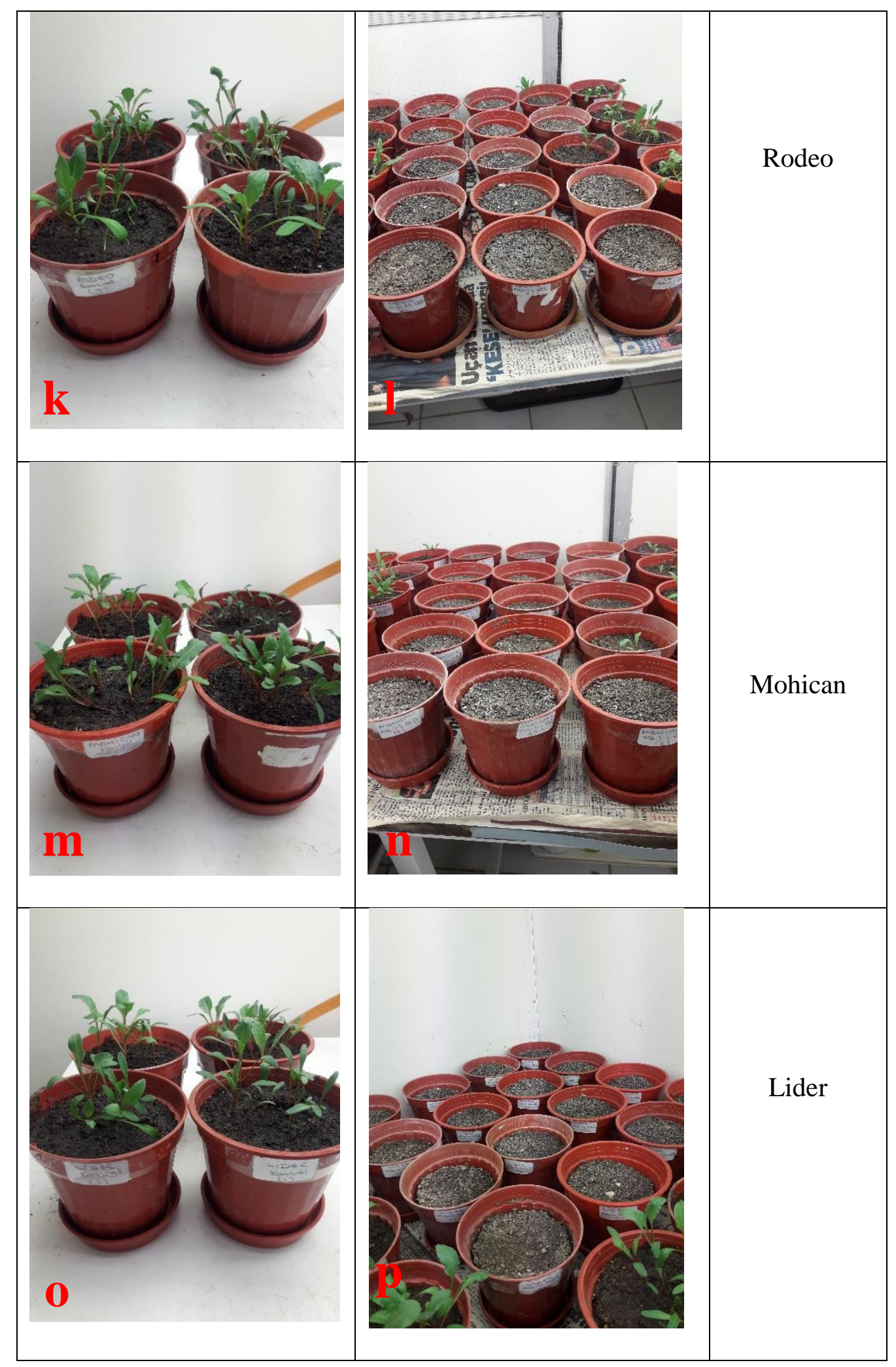




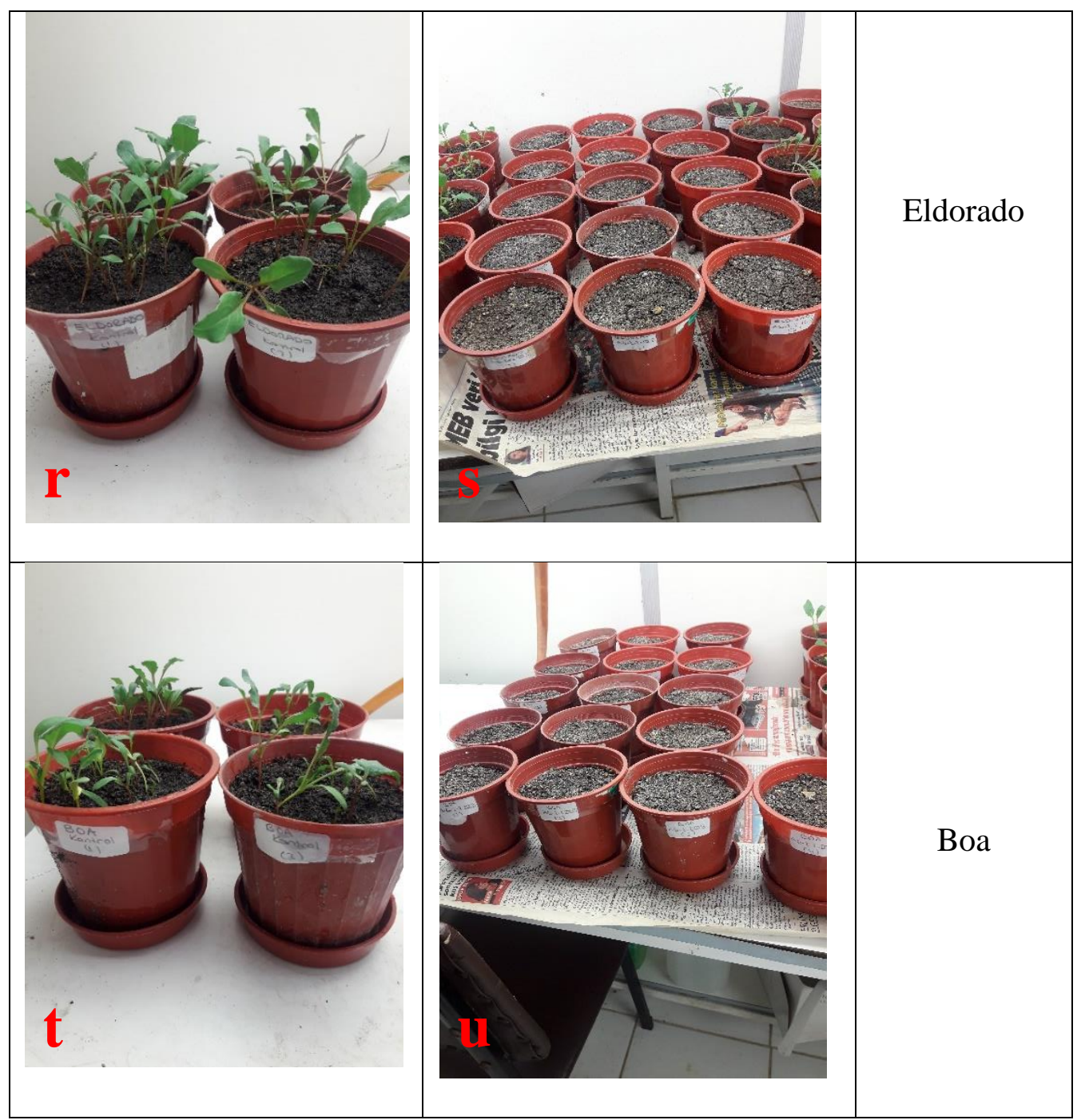

Şekil 2. Tüm çeşitlere ait kontrol gruplar ve multinükleat Rhizoctonia solani AG-2-2-IIIB, AG-4-HGI, AG-4-HGII, AG-4-HGIII izolatlarının çeşitlere etkisi 
3.2. Dayanıklı Şeker Pancarı Çeşitlerinin Binükleat Rhizoctonia spp. AG-A, AG-K İzolatlarına Karşı Reaksiyonları

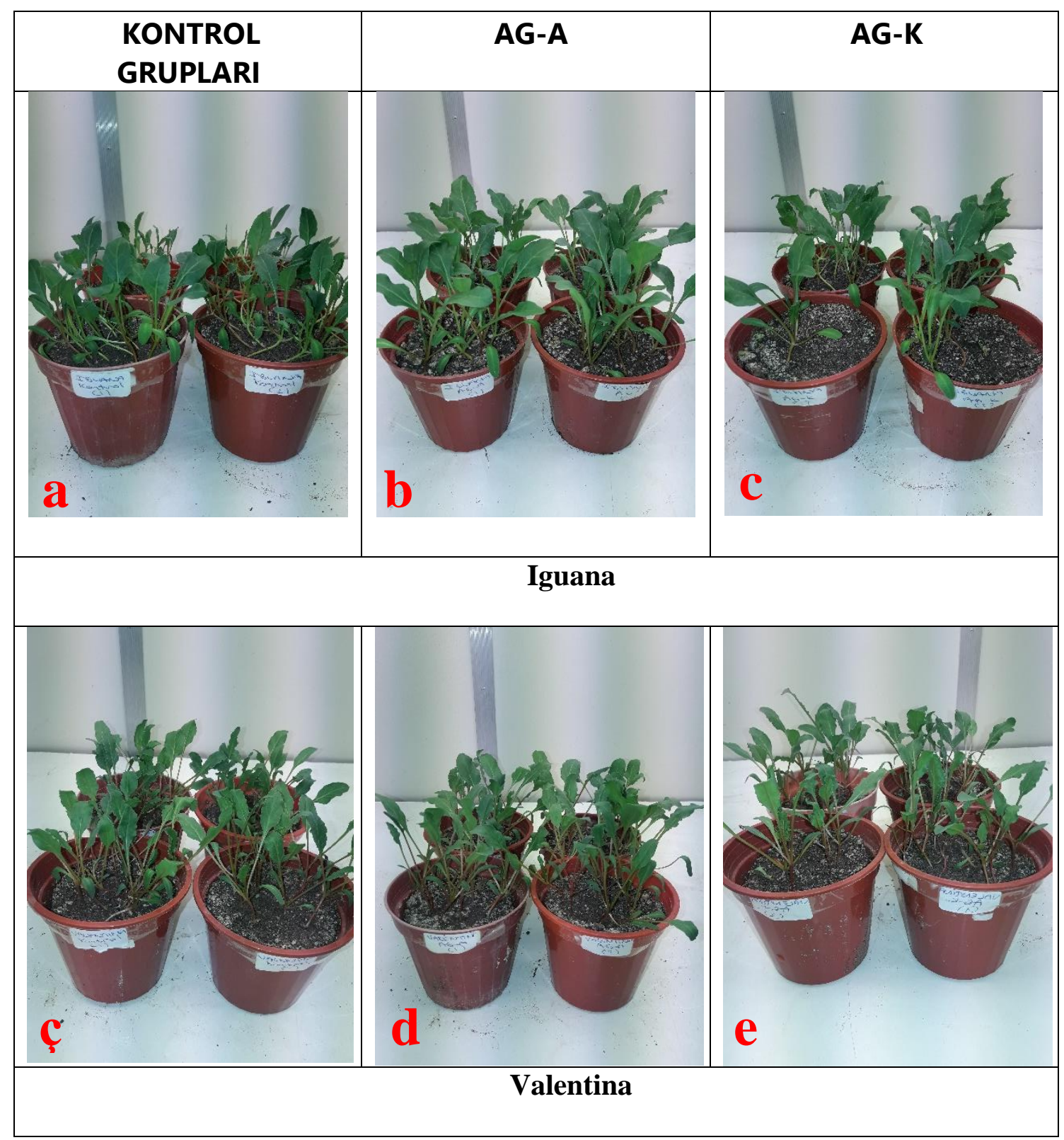




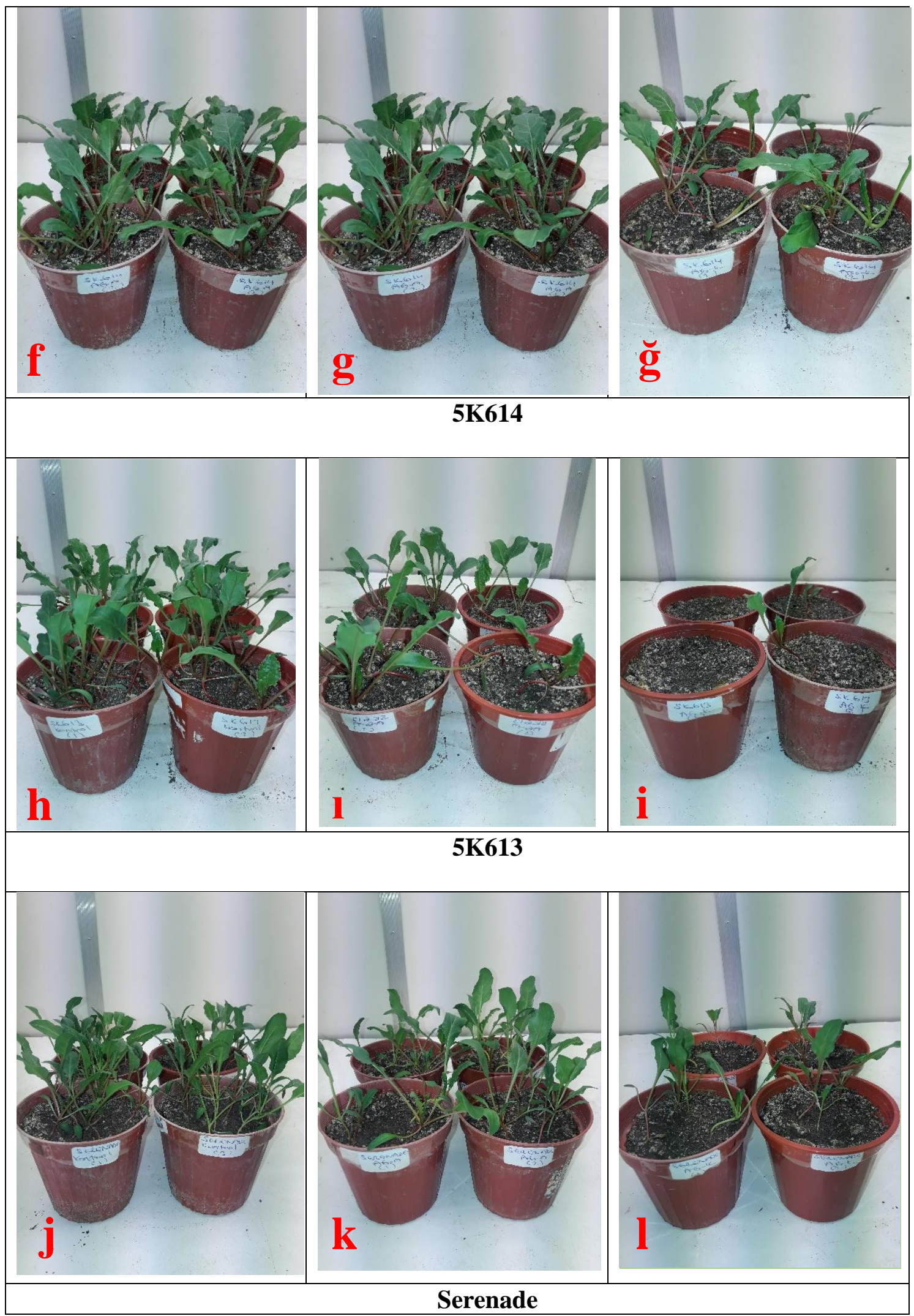


(2020) 2(2):275-295

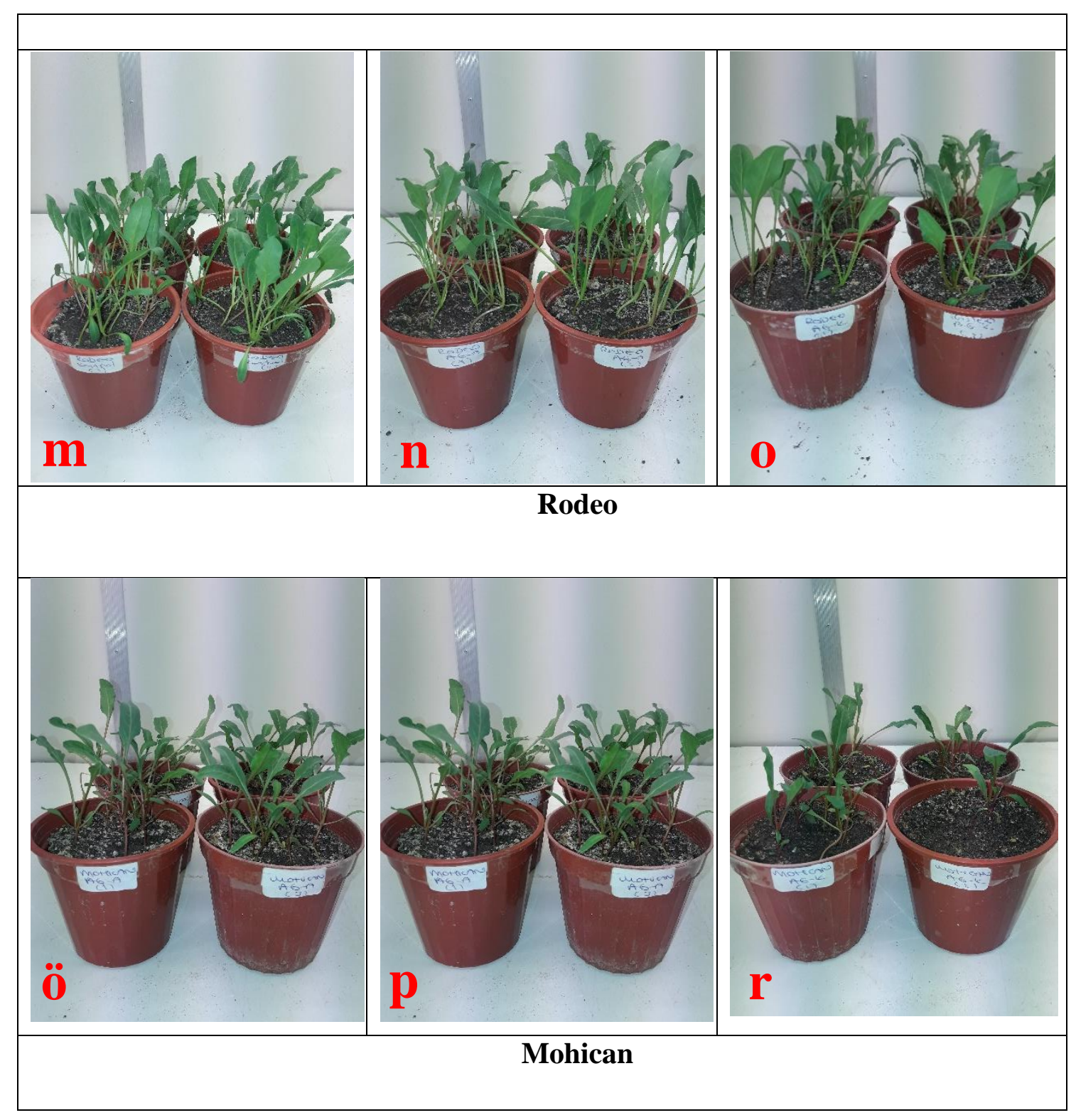



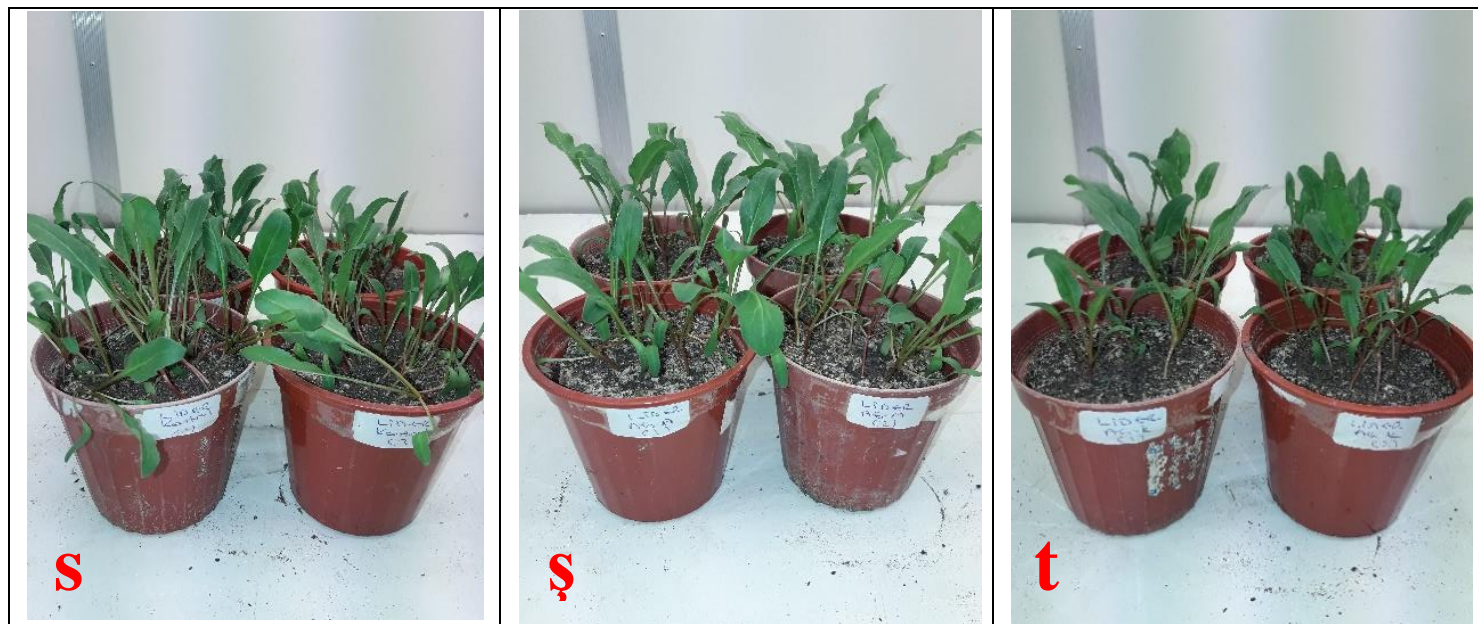

\section{Lider}
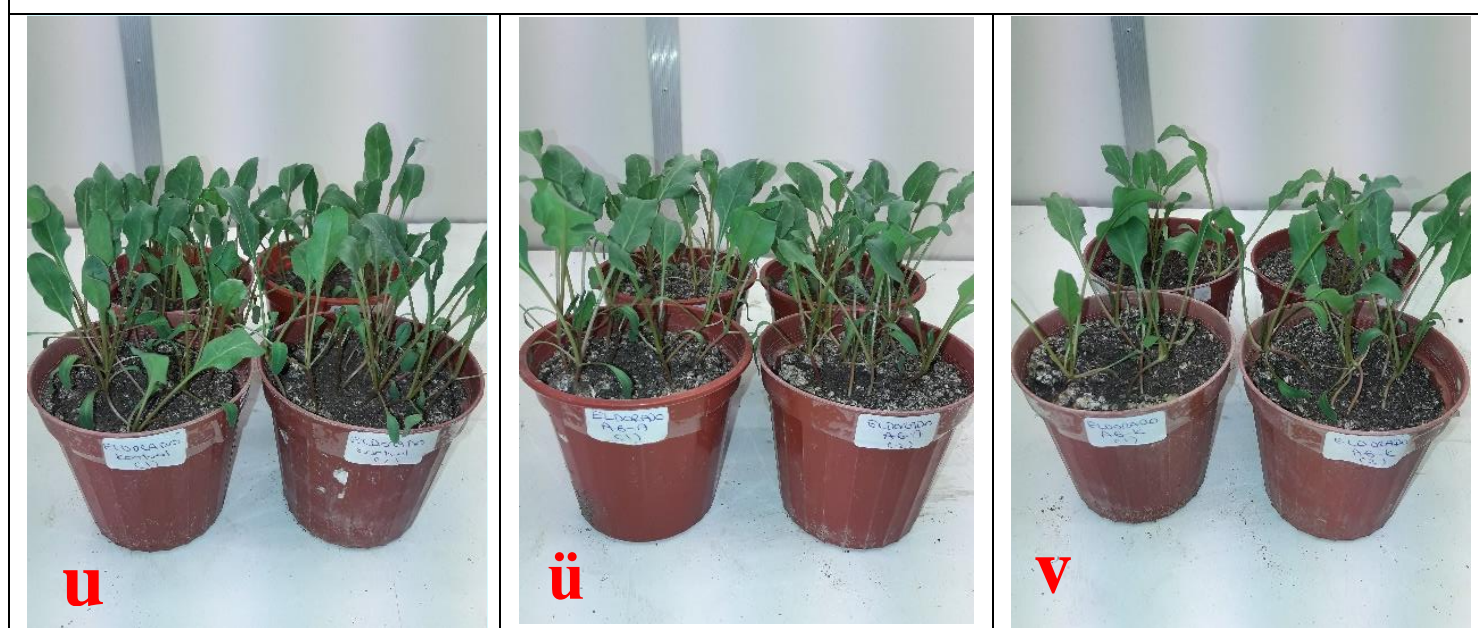

Eldorado
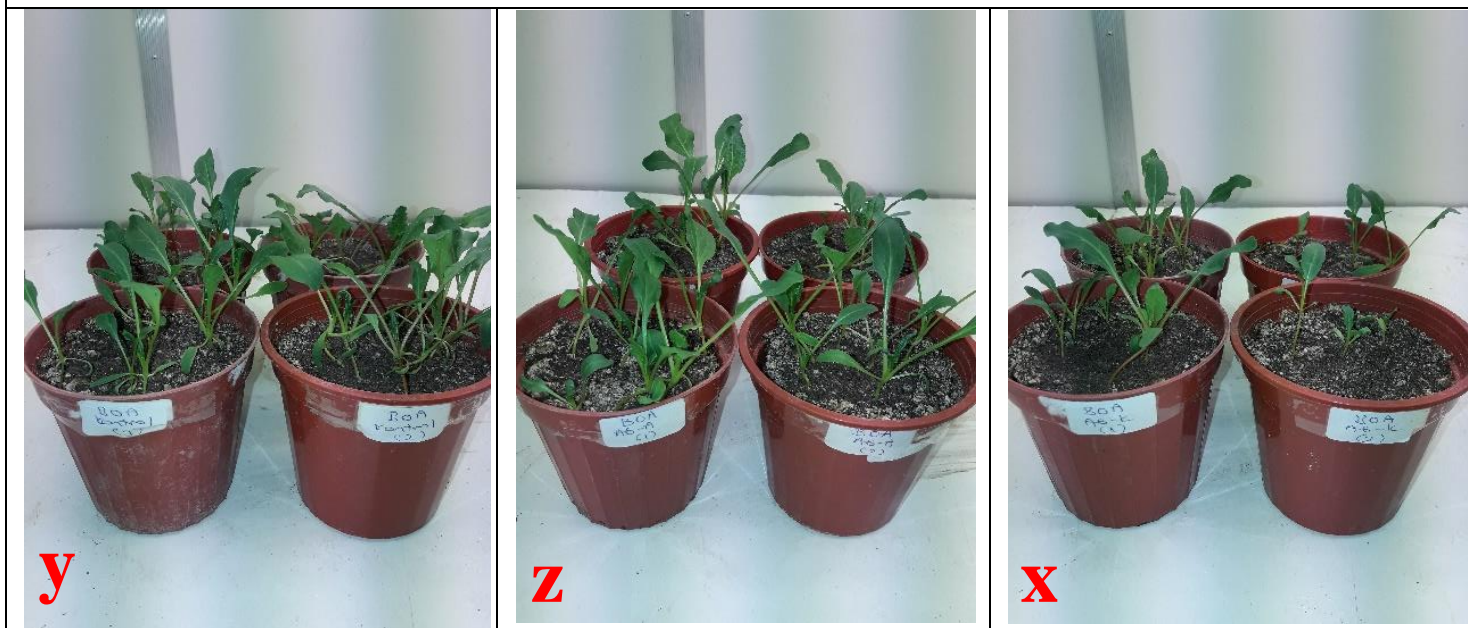

Boa 
Avan, M., Katırcıoğlu, Y.Z., Uluslararası Doğu Anadolu Fen Mühendislik ve Tasarım Dergisi / International Journal of Eastern Anatolia Science Engineering and Design (IJEASED)

(2020) 2(2):275-295

Şekil 3. Tüm çeşitlere ait kontroller ve binükleat Rhizoctonia spp. AG-A ve AG-K izolatlarının çeşitlere etkisine ait deneme sonuçları

Tablo 2. Çeşitler ile AG-A ve AG-K izolatlar arasındaki Kruskal-Wallis test yöntemi ile çoklu ve tüm ikili karşılastırmaların sonuçları

\begin{tabular}{|c|c|c|}
\hline \multirow[t]{2}{*}{ ÇEŞITTLER } & \multicolumn{2}{|r|}{ AG-A ve AG-K için } \\
\hline & $\begin{array}{l}\text { Çoklu } \\
\text { Karşılaştırma }\end{array}$ & Tüm ikili karşılaştırmalar \\
\hline Boa & $\mathrm{P}=0,012<0,05$ & Kontrol--AG-K=0,00321<0,01 \\
\hline Eldorado & $\mathrm{P}=0,006<0,05$ & Kontrol--AG-K=0,00137<0,01 \\
\hline Iguana & $\mathrm{P}=0,01<0,05$ & Kontrol--AG-K=0,00332<0,01 \\
\hline Lider & $\mathrm{P}=0,006<0,05$ & Kontrol--AG-K=0,00149<0,01 \\
\hline Mohican & $\mathrm{P}=0,012<0,05$ & Kontrol--AG-K=0,0031<0,01 \\
\hline Rodeo & $\mathrm{P}=0,006<0,05$ & Kontrol--AG-K=0,00137<0,01 \\
\hline Serenade & $\mathrm{P}=0,006<0,05$ & Kontrol--AG-K=0,00137<0,01 \\
\hline Valentina & $\mathrm{P}=0,069>0,05$ & $\begin{array}{l}\text { AG-A ve AG-K arasında gözlenen endeks } \\
\text { değerleri bakımından gözlenen farkların istatistik } \\
\text { olarak önemli değildir. }\end{array}$ \\
\hline $5 \mathrm{~K} 613$ & $\mathrm{P}=0,011<0,05$ & Kontrol--AG-A=0,00313<0,01 \\
\hline $5 \mathrm{~K} 614$ & $\mathrm{P}=0,006<0,05$ & Kontrol--AG-K=0,00146<0,05 \\
\hline
\end{tabular}

Yapılan çalışmalar sonucunda AG-A ve AG-K anastomosis gruplarına ait agresif izolatların Boa, Eldorado, Iguana, Lider, Serenade, Valentina, 5K613 ve 5K614 isimli çeşitlere karşı sonuçları istatistiki değerlendirilmesi ile farkı önemli bulunmuştur. Yapılan istatistikler sonucunda:

Boa, Eldorado, Iguana, Lider,Mohican, Rodeo, Serenade, 5K614 çeşidinin AG-A ve AG-K grupları arasındaki farkın istatistiksel olarak önemli olduğunu göstermiştir $(\mathrm{P}<0.05)$. Yapılan çoklu karşılaştırma yöntemi ile kontrol grubu ile AG-K izolatları arasındaki farkın istatistiksel olarak önemli olduğu saptanmıştır $(\mathrm{P}<0.01)$.

5K613 çeşidinin AG-A ve AG-K grupları arasındaki farkın istatistiksel olarak önemli olduğunu göstermiştir $(\mathrm{P}<0.05)$. Yapılan çoklu karşılaştırma yöntemi ile kontrol grubu ile AG-A izolatları arasındaki farkın istatistiksel olarak önemli olduğu saptanmıştır $(\mathrm{P}<0.01)$.

Valentina çeşidinin AG-A ve AG-K grupları arasındaki farkın istatistiksel olarak önemli olmadığı sonucuna varılmıştır ( $\mathrm{P}>0.05)$. Dolayısıyla BN Rhizoctonia anastomosis grupları olan AGA ve AG-K izolatlarının birbirleri arasındaki farkı önemli değilken, çeşitler arasındaki farkları önemli bulunmuştur (Tablo 2). 
Tablo 3. Çeşitlerin ve MN Rhizoctonia solani ve BN Rhizoctonia spp.'ye ait 6 anastomosis grubunun agresif izolatlarına ait \% etkileri ve hastalık şiddeti göre dayanıklılık seviyesi gruplamaları

\begin{tabular}{|c|c|c|c|c|c|c|}
\hline Çeşitler & $\begin{array}{l}\text { AG-2-2- } \\
\text { IIIB }\end{array}$ & $\begin{array}{l}\text { AG-4- } \\
\text { HGI }\end{array}$ & $\begin{array}{l}\text { AG-4- } \\
\text { HGII }\end{array}$ & $\begin{array}{l}\text { AG-4- } \\
\text { HGIII }\end{array}$ & AG-A & AG-K \\
\hline Boa & $0(\mathrm{~S})$ & $0(\mathrm{~S})$ & $0(\mathrm{~S})$ & $0(\mathrm{~S})$ & 58 (MR) & 45 (LR) \\
\hline Eldorado & $0(\mathrm{~S})$ & $0(\mathrm{~S})$ & $0(\mathrm{~S})$ & $0(\mathrm{~S})$ & 93 (HR) & 50 (MR) \\
\hline Iguana & $0(\mathrm{~S})$ & $0(\mathrm{~S})$ & $0(\mathrm{~S})$ & $0(\mathrm{~S})$ & 100 (HR) & 70 (MR) \\
\hline Lider & $0(\mathrm{~S})$ & $0(\mathrm{~S})$ & $0(\mathrm{~S})$ & $0(\mathrm{~S})$ & 92 (HR) & 85 (HR) \\
\hline Serenade & $0(\mathrm{~S})$ & $0(\mathrm{~S})$ & $0(\mathrm{~S})$ & $0(\mathrm{~S})$ & 70 (MR) & 28 (LR) \\
\hline Valentina & $0(\mathrm{~S})$ & $0(\mathrm{~S})$ & $0(\mathrm{~S})$ & $0(\mathrm{~S})$ & 95 (HR) & 80 (HR) \\
\hline Mohican & $0(\mathrm{~S})$ & $0(\mathrm{~S})$ & $0(\mathrm{~S})$ & $5(\mathrm{~S})$ & 66 (MR) & 50 (MR) \\
\hline Rodeo & $0(\mathrm{~S})$ & $0(\mathrm{~S})$ & $0(\mathrm{~S})$ & $10(\mathrm{~S})$ & $93(\mathrm{HR})$ & 68 (MR) \\
\hline $5 \mathrm{~K} 613$ & $0(\mathrm{~S})$ & $0(\mathrm{~S})$ & $0(\mathrm{~S})$ & $0(\mathrm{~S})$ & 33 (LR) & 56 (MR) \\
\hline $5 \mathrm{~K} 614$ & $0(\mathrm{~S})$ & $0(\mathrm{~S})$ & $0(\mathrm{~S})$ & $0(\mathrm{~S})$ & 80 (HR) & 56 (MR) \\
\hline
\end{tabular}

[Towsend-Heuberger formülüne göre hastalık şiddeti hesaplanarak dayanıklılık seviyesi gruplamaları $(\mathrm{I}=\leq \% 20$ : Yüksek düzeyde dayanıklı (HR), II= \% 21-50: Orta düzeyde dayanıklı (MR), III= \% 51-80: Düşük düzeyde dayanıklı (LR), IV=>\% 80: Duyarlı (S)]

Çalışmada 10 adet dayanıklı şeker pancarı çeşitleri ile beraber, BN Rhizoctonia spp.'lerden AG-K ve AG-A'ya ait en yüksek virülensliğe sahip izolatları ve her bir çeşite ait kontrol saksılarının (Şekil 3 a, ç, f, h, j, m, ö, s, u, y) 4 tekerrürlü olarak denenmesi sonucu, AG-A izolatı için Iguana (Şekil 3 b), Valentina (Şekil 3 d), Eldorado (Şekil 3 ü), Rodeo (Şekil 3 n) ve Lider ç (Şekil 3 ş), 5K614 çeşitlerinde (Şekil 3 g) yüksek düzeyde dayanıklılık (HR) olduğu ve Serenade çeşidinde (Şekil $3 \mathrm{k}$ ) ise orta düzeyde dayanıklılık (MR) olduğu tespit edilmiştir. 5K613 çeşidinin (Şekil 3 1) ise düşük düzeyde dayanıklı (LR) olduğu bulunmuştur. AG-K izolatı için Lider (Şekil 3 t) ve Valentina çeşidi (Şekil 3 e) yüksek düzeyde dayanıklı (HR) bulunurken, Eldorado (Şekil 3 v), Iguana (Şekil 3 c), Mohican (Şekil 3 r), Rodeo (Şekil 3 o), 5K613 (Şekil 3 i)ve 5K614 (Şekil 3 ğ) çeşitlerinde ise orta düzeyde dayanıklılık olduğu gözlemlenmiştir. Düşük düzeyde dayanıklı (LR) olan çeşit olarakta Serenade (Şekil 3 1) çeşidinin olduğu gözlemlenmiştir (Tablo 3).

Bu çalışmanın amac1, Rhizoctonia taç ve kök çürüklüğü ve çökertene neden olan Rhizoctonia solani ve binükleat Rhizoctonia spp. 'ye karşı dirençli şeker pancarı çeşitlerini test etmek ve sera ile tarla koşullarında uygun teknikleri geliştirmek için bir yol açmayı sağlamaktır. Şeker pancarının tarladaki Rhizoctonia kök çürüklüğü ve çökertene karşı direncinin test edilmesinde, Rhizoctonia fungusunun öngörülemeyen bir şekilde ve çoğunlukla düzensiz olarak birden ortaya çıkabilmekte ve hastalık çevresel faktörlerden de çok fazla etkilenebilmektedir. Aynı zamanda iklim odasında 
yapılan çalışmalarda Rhizoctonia kök çürüklüğünün oluşumu için hem konukçu bitkinin hem de Rhizoctonia'nın spesifik gereksinimlerinin dikkate alınması oldukça önemlidir (Dhingra ve Sinclair, 1995). Tarlada test koşulları hassas olarak ayarlanmış olsa bile ilkbaharda yapılan tarla denemeleri ile yaz sonu ya da sonbaharda yapılan denemeler arasında yetersiz 1şıktan kaynaklanan yavaş enfeksiyon gelişimi ve hastalık seyrinde azalmalar meydana gelmektedir (Scholten ve ark., 2001). $\mathrm{Bu}$ açıdan iklim odası denemeleri tarla denemelerine, önemli bir alternatif metod olarak sunulmaktadir.

Denemeler sonucunda, multinükleat olan 4 anastomosis grubu AG-2-2-IIIB, AG-4-(HGI, HGII, HGIII); BN, 2 anastomosis grubu olan AG-A ve AG-K ile çeşitlerin reaksiyonu kontrollü iklim odası çalışmalarında Rhizoctonia izolatlarına (AG-2-2-IIIB, AG-4-HGI, AG-4-HGII, AG-4HGIII) karşı kullanılan 10 çeşidin hepsinin de dayanıklı olmadığı, AG-A ve AG-K izolatları için de kısmen dayanıklı çeşitler olarak da Lider ve Valentina çeşitleri olduğu tespit edilmiştir. Büttner ve ark. (2004) şeker pancarı kök çürüklüğünün entegre kontrol stratejisinin ana çözüm kaynağının dayanıklı şeker pancarı çeşitleri olduğunu ifade etmiştir. Yapmış olduğu çalışmasında kullanmış olduğu dayanıklı tüm şeker pancarı çeşitlerinin $R$. solani'den etkilendiğini fakat kısmen dirençli çeşitler olduğunu bildirerek bizim çalışmamızda paralel sonuçlara erişmiş̧tir. Halloin ve Johnson (2000) çalışmalarında, dirençli ve hassas farklı şeker pancarı çeşitlerinin karışımlarını ekerek, karışımda dirençli çeşit miktarını artırdıkça hastalık ve buna bağlı verim kayıpları azaldığını tespit etmişlerdir. Engelkes ve Windels (1996), Şeker pancarı, soya fasulyesi ve fasulye çeşitlerinin özellikle R. solani AG 2-2 IIIB ve AG-2-2-IV'e karşı oldukça hassas olduğunu bildirmiştir. Ayrıca $R$. solani'ye dayanıklı çeşitlerin olduğunu fakat genellikle bunların ekimde çok fazla tercih edilmediğini ifade etmişlerdir. Oysa hastalık gelişimini bilmenin zor olduğunu ve hastalığın az yada olmadığı zamanlarda hassas çeşitlerin dayanıklı çeşitlere göre daha fazla verim potansiyeline sahip olduğunu bildirmişlerdir. Bizim çalışmamızda kullandığımız bu 10 adet dayanıklı şeker pancarı çeşidinin $R$. solani 'nin AG-2-2-IIIB'ye karşı dayanıklı bulunmayıp duyarlı olduğu tespit edildiği gibi aynı zamanda AG-4-(HGI, HGII, HGIII) anastomosis gruplara karşı da hassas oldukları tespit edilmiştir.

Ülkemizde şeker pancarı için Rhizoctonia türlerinin çeşit reaksiyonlarına ait detaylı bir çalışma bulunmamaktadır. Dünya' da ise bu konuda yapılan çalışmalar çok kısıtlıdır. Yine dünyada yapılanlar ile bu yaptığımız bu çeşit reaksiyon çalışmasında, şeker pancarı çeşitlerinin Rhizoctonia 
türlerine karşı hassas olduğu görülmektedir. Özellikle Rhizoctonia AG-2-2-IIIB başta olmak üzere AG-4-(HGI, HGII, HGIII) grubu izolatlara karşı çeşitler oldukça dayanıksız bulunmuştur.

\section{Sonuçlar ve Öneriler}

Dayanıklı şeker pancarı çeşitlerinin, virülensliği \%100 olan mültinükleat Rhizoctonia solani izolatlarına karşı hiç bir dayanıklılık gösteremediği, virülensliği \%53 ile düşük virülens ve \%69 ile orta virülens binükleat Rhizoctonia spp. izolatlarına karşı diğer virülensliği yüksek izolatlara oranla, kısmi bir dayanıklılık görüldüğü tespit edilerek, şeker pancarına karşı dayanıklı çeşit geliştirme konusunda ve patojenin direncini değerlendirmede farklı bir bakış açısı getirilerek konuya katkılar sağlamaktadır.

Yaz dönemi dışında yapılan tarla denemelerinde yetersiz 1şık alımı nedeniyle, patojenin gelişiminin yavaşlaması, hastalığın daha yavaş ilerleyişi dolayısıyla hastalığın seyrinde gerilemelere sebebiyet verdiğinden dolayı meydana gelebilecek bu olumsuz sonuçlara bir alternatif olarak yapmış olduğumuz iklim odası çalışmaları hastalıkla mücadelede bir ışık tutmuştur.

\section{Teșekkür}

$\mathrm{Bu}$ çalışma, $115 \mathrm{O} 562$ nolu TÜBİTAK projesinde elde edilen bitki örneklerinden ve 18L0447014 nolu Ankara Üniversitesi BAP Projesi ile finanse edilen proje sonuçlarının bir kısmını içermektedir. Yazarlar ayrıca Ankara Şeker Enstitüsünden Dr. Rıza Kaya’ya ve arazi çalışmasına katkıları nedeniyle Torku, Konya Şeker ve Ilgın şeker fabrikalarına teşekkür ederler.

Not: Bu çalışma Meltem AVAN'ın doktora tezinden üretilmiştir.

\section{Kaynaklar}

Abbott, W. S. (1925). A method of computing the effectiveness of an insecticide. Journal of Economic Entomology, 18:265-267.

Ajayi-Oyetunde, O. O., ve Bradley, C. A. (2017). Identification and characterization of Rhizoctonia species associated with soybean seedling disease. Plant Disease, 101(4), 520-533.

Anonim (2017). T.C. Şeker Kurumu 2016 Y1l Faaliyet Raporu. 26.05.2017 Ankara.

Avan, M. (2020). Konya bölgesi şeker pancarı ekim alanlarında görülen Rhizoctonia türlerinin karakterizasyonu ve mücadelesi üzerine araştırmalar (Yayımlanmamış doktora tezi). Ankara Üniversitesi Fen Bilimleri Enstitüsü, Ankara 
Berdugo, C., Hillnhütter, C., Sikora, R. ve Oerke, E. C. (2012). A Resistance Bioassay for Rhizoctonia Root and Crown Rot and Damping-off Caused by the Anastomosis Groups AG 2-2IIIB and AG 4 in Sugar Beet. Journal of Agricultural Science and Technology. A, 2(3A), 294.

Buddemeyer, J., ve Märländer, B. (2004). Integrated control of crown rot in sugar beet roots (Rhizoctonia solani Kühn) - the impact of tillage factors, crop rotation, and selection of varieties, including maize. Zuckerindustrie, 129, 799-809.

Büttner, G., Pfähler, B., ve Märländer, B. (2004). Greenhouse and field techniques for testing sugar beet for resistance to Rhizoctonia root and crown rot. Plant breeding, 123(2), 158-166.

Carling, D. E., Baird, R. E., Gitaitis, R. D., Brainard, K. A. ve Kuninaga, S. (2002). Characterization of AG13 a newly reported anastomosis group of Rhizoctonia solani. Phytopathology, 92(8), 893-899.

Dhingra, O. D., ve Sinclair, J. B. (1995). Basic Plant Pathology Methods. 2nd edn. CRC Lewis Publishers, Boca Raton, London.

Dong, W. H., Li, Y. Q., Duan, C. F., Li, X. G., Naito, S., Conner, R. L., vd. (2017). Identification of AG-V, a new anastomosis group of binucleate Rhizoctonia spp. from taro and ginger in Yunnan province. European Journal of Plant Pathology, 148(4), 895-906.

Engelkes, C. A., ve Windels, C. E. (1996). Susceptibility of sugar beetand beans to Rhizoctonia solani AG-22 IIIb and AG-2-2 IV. Plant Disease, 80, 1413-1417.

FAOSTAT, (2019). Food and Agriculture Organization of the United Nations [online]. Website http://www.fao.org/faostat/en/\#data/QC/visualize (accessed on 12.12.2019).

García, V.G., Portal Onco, M. A. ve Susan, V. R. (2006). Review. Biology and Systematics of the form genus Rhizoctonia. Spanish Journal of Agricultural Research, 4(1), 55-79.

González Garcia, V., Portal Onco, M. A., ve Rubio Susan, V. (2006). Review. Biology and systematics of the form genus Rhizoctonia. Spanish Journal of Agricultural Research, 4, 55-79.

Halloin, J. M., ve Johnson, D. J. (2000). Reduction of sugarbeet losses from Rhizoctonia crown and root rot by use of mixtures of resistant and susceptible varieties. Phytopathology, 90.

Hanson, L. E. (2006). First report of Fusarium yellows of sugar beet caused by Fusarium oxysporum in Michigan, Plant Disease, 90, 1554.

Herr, L. J., ve Roberts, D. L. (1980). Characterization of Rhizoctonia populations obtained from sugarbeet fields with differing soil textures. Phytopathology, 70(6), 476-480.

Herr, L. J. (1996). Sugar beet disease incited by Rhizoctonia solani spp. In Rhizoctonia Species: Taxonomy, Molecular Biology, Ecology, Pathology and Disease Control, 341-349. Kluwer Academic Publ., The Netherlands.

Ogoshi, A. (1987). Ecology and pathogenicity of anastomosis and intraspecific groups of Rhizoctonia solani Kühn. Annual Review of Phytopathology, 25, 125-143.

Pierson, V. G., ve Gaskill, J. O. (1961). Artificial exposure of sugar beets to Rhizoctonia solani. Journal of the American Society of Sugar Beet Technologists, 11, 574-590.

Scholten, O. E., Panella, L. W., De Bock, T. S. M., ve Lange, W. (2001). A greenhouse test for screening sugar beet (Beta vulgaris) for resistance to Rhizoctonia solani. European Journal of Plant Pathology, 107, 161-166.

Townsend, G. K., ve Heuberger, J. W. (1943). Methods for estimating losses caused by diseases in fungicide experiments. Plant Disease Report, 27, 340-343.

Wang, P. P., ve Wu, X. H. (2012). First report of sugar beet seedling damping-off caused by binucleate Rhizoctonia AG-A in China. Plant disease, 96(11), 1696-1696.

Windels, C. E. ve Nabben, D. J. (1989). Characterization and pathogenicity of anastomosis groups of Rhizoctonia solani isolated from Beta vulgaris. Phytopathology, 79(1), 83-88.

Yang, Y. G., Zhao, C., Guo, Z. J. ve Wu, X. H. (2015a). Anastomosis group and pathogenicity of Rhizoctonia solani associated with stem canker and black scurf of potato in China. European Journal of Plant Pathology, 143(1), 99-111. 
Yang, Y. G., Zhao, C., Guo, Z. J. ve Wu, X. H. (2015b). Characterization of a new anastomosis group (AGW) of binucleate Rhizoctonia, causal agent for potato stem canker. Plant Disease, 99(12), 1757-1763.

Zhao, C., Li, Y., Wu, S., Wang, P., Han, C., ve Wu, X. (2019). Anastomosis group and pathogenicity of Rhizoctonia spp. associated with seedling damping-off of sugar beet in China. European Journal of Plant Pathology, 153(3), 869-878. 